AGH DRILLING, OIL, GAS • Vol. $29 \cdot$ No. $3 \cdot 2012$

http://dx.doi.org/10.7494/drill.2012.29.3.411

\author{
Dan-Maniu Duse*, Carmen Sonia Duse*
}

\title{
INFLUENCES OF THE ORGANIZATIONAL CULTURE ON MANAGEMENT CHANGE AND FACULTY DEVELOPMENT IN NATURAL GASES ENGINEERING EDUCATION
}

\section{INTRODUCTION}

The study on organizational culture in LBU was done during the 2011 year, by interviewing a number of 648 academic staff members from all faculties that compose the University. In order to determine the research sample, the stratified sampling and percentage based on percentage quotas were used. The questionnaire used to determine the cultural dimensions was based on the works of Dutch researcher Geert Hofstede (2005).

The research had the following objectives:

- determining the typology of the organizational culture in LBU;

- highlighting the values of the academic staff;

- creating a base for comparing with other academic organizational cultures, in different contexts;

- identifying the action areas for managers in order to increase education and research quality, in natural gases engineering education;

- drawing the necessary conclusions for managers to resize and capitalize on the elements of organizational culture.

The following hypotheses were considered in approaching the research:

H1. The cultural dimensions of LBU will converge with those at national level, meaning high power distance, femininity, collectivism and high uncertainty avoidance.

H2. A culture oriented towards feminine values and a relatively high uncertainty avoidance shape the profile of employees where the need for security, engagement, a positive working climate and an accent on communication and motivation prime.

* Lucian Blaga University of Sibiu, Romania 
H3. In a culture with highly collectivist values and with a tendency for femininity, the community members will be preoccupied in assuring client satisfaction; the individual will be engaged and will respect the common values of the group.

H4. Individuals from a collectivist culture prefer the security provided by the living environment and will respect the existing traditions of the group. After processing the results, the following dimensions were determined.

\section{THE ORGANIZATIONAL CULTURE OF "LUCIAN BLAGA" UNIVERSITY}

Collectivism. At university level, there is a strong collectivism (68.18\%). The closest explanation could be the correspondence between the researched dimension and the results at national level. For a collectivist society, the most stringent requirements regarding the work place are:

- to benefit from periodical training to improve performance or even gain new abilities;

- to have good physical working conditions;

- to be able to fully use your qualifications and competencies.

Collectivism is more favoured by academic staff aged 35-45 that have been within the organisation for 11-15 years.

Femininity. Without being a very strong one, the score for the entire university is $59.09 \%$ in favour of femininity. The lowest scores were obtained by the Faculty of Medicine $(27.27 \%)$ and Engineering (31.81\%), while the most feminine groups are the Educational Science Department (63.63\%), History and Patrimony $(77.27 \%)$ and Journalism $(79.5 \%)$.

Short term orientation of the university refers to identifying the concerns for keeping certain traditions within the institution in order to fulfil the social obligations as much as the system allows it through its specific norms, rules and laws. Short term oriented cultures accentuate femininity, personal stability, a good reputation, social finesse. By analysing the questionnaires, a short term orientation of the interviewed staff is visible $(59.09 \%)$.

By faculty, short term orientation is visible in Medicine (84\%) followed by the Faculty of Journalism (79\%). But the Educational Science Department is, with $29.5 \%$ long term oriented, and followed by Economic Sciences (25\%) then Law and History (18.8\%). Women tilt the scale towards short term orientation, as well as members who have been with the organisation 11-15 years.

Low power distance. Research has revealed a medium-low distance to power $(51.82 \%)$, as opposed to the national dimension. Faculties with a higher power distance are Engineering and Medicine, followed by History, Law and Theology. But it must be noted that obtained values are just below the median (50\%), so we are not talking of a truly high power distance between the faculties' management and the academic staff.

Middle aged employees (35-45 years) see the power distance smaller as those under 35 or above 45 years old. Men also feel closer to power. 
Uncertainty avoidance at university level (77.27\%) is in accord with the national one. Most faculties and groups have scores above 50\% for high uncertainty avoidance. The most visible is the Faculty of Economic Sciences, Theology, Journalism and Political Sciences. This situation is understandable if we consider the current situation in the educational environment, both universities and pre-university education.

Women have higher uncertainty avoidance $(63 \%)$, as well as people aged 46-55 $(59 \%)$.

All these are signs of a wish for uniformity and standardization. In such a culture, managers have a low tendency towards individual risks and decisions. The values promoted by the academic staff in LBU are: order, network, survival, learning, personal success, safety, people and lastly power. The organizational values ranked as follows:

- first place is for "lawfulness" (79.9\%);

- followed by professionalism $(73.3 \%)$;

- respect $(71.7 \%)$;

- quality of work done $(70 \%)$;

- competency, perseverance, security and continuous learning (70\%);

- responsibility (69.3\%);

- gained performance $(69.1 \%)$;

- pleasant working climate $(65.5 \%)$;

- work ethics $(65.1 \%)$;

- being organized (65\%);

- work autonomy $(64.7 \%)$;

- efficiency $(64.4 \%)$;

- discipline $(69.3 \%)$;

- engagement/involvement (68.5\%);

- correctness $(60.3 \%)$;

- client satisfaction, trust and tradition (59.9\%);

- innovation/creativity (54.5\%).

All these values talk about work consciousness and the seriousness of the academic staff. But what is in fact the link between the organizational culture, the personnel values and the organizational change, or how do they influence performance management within the organization?

\section{CHANGE AND DEVELOPMENT IN NATURAL GASES ENGINEERING EDUCATION}

It is common knowledge that a strong culture, with deep roots and carefully connected to the organizational strategy, but also with the tendencies of the external environment, will always bring success to the organization, while a weak surface culture is mainly an obstacle 
in constructing an organizational strategy (Sackmann, 2001). In this context, culture has a double role: it creates internal unity and helps the organization adapt to the external environment.

In order to better understand how the culture of LBU works, especially in natural gases engineering education we must accept these cultural dimensions as being variable between certain set limits (Fig. 1). This means that we can accept that the dimensions can have different numeric values and the management must accept all fluctuations and foresee solutions for each one of them.

\section{Low collectivism, low wish for change}

Weak links exist between individuals, communication is formal, and there is a low wish for change. A dangerous status-quo appears within the organization. Management is forced to act in order to achieve group cohesion and a step by step acceptance of small organizational changes.

This step has the risk of insular thinking, where individuals in the organization consider that only they have answers for all questions, and everything that doesn't fall under their acceptance must be aborted.

\section{Low collectivism, high wish for change}

Individuals do not find their place within the organization; small spurts of increased individualism appear. Change is demanded and caused, because the organization is focused towards the external environment. Management can make changes, but attention to the frail organizational culture is required. Low collectivism can easily fall apart, leading to the organization's demise. Also, conflicts are inherent, with all their effects, sometimes even dramatic.

High collectivism, low wish for change:

Inevitably, the climate is highlighted by group unity, with maintaining the current status. There is a high expression of femininity. Correlated with high uncertainty avoidance, change can sometimes be completely blocked. There is a high risk for bureaucratization because of this pronounced conservatism.

What should the management's reaction be in such a situation? Most certainly, a plead for implementing step by step changes, according to the new education law. This must be done by appealing to emotional arguments, by creating pro-change waves. Management must also accept the idea that change will be done in small but constant steps.

There is a risk of turning into a bureaucratic organization, with all the subsequent consequences.

High collectivism, high wish for change:

For the current situation in Romania, this is the ideal state, because current legislative provisions require compliance and subjection to the new objectives. If this collectivism 
would proactively manifest itself for change, the first thing that would be easily set into practice would be the remodelling of the university, its reorganization under closed organizational structures which will have a more consistency, both scientifically and educationally.

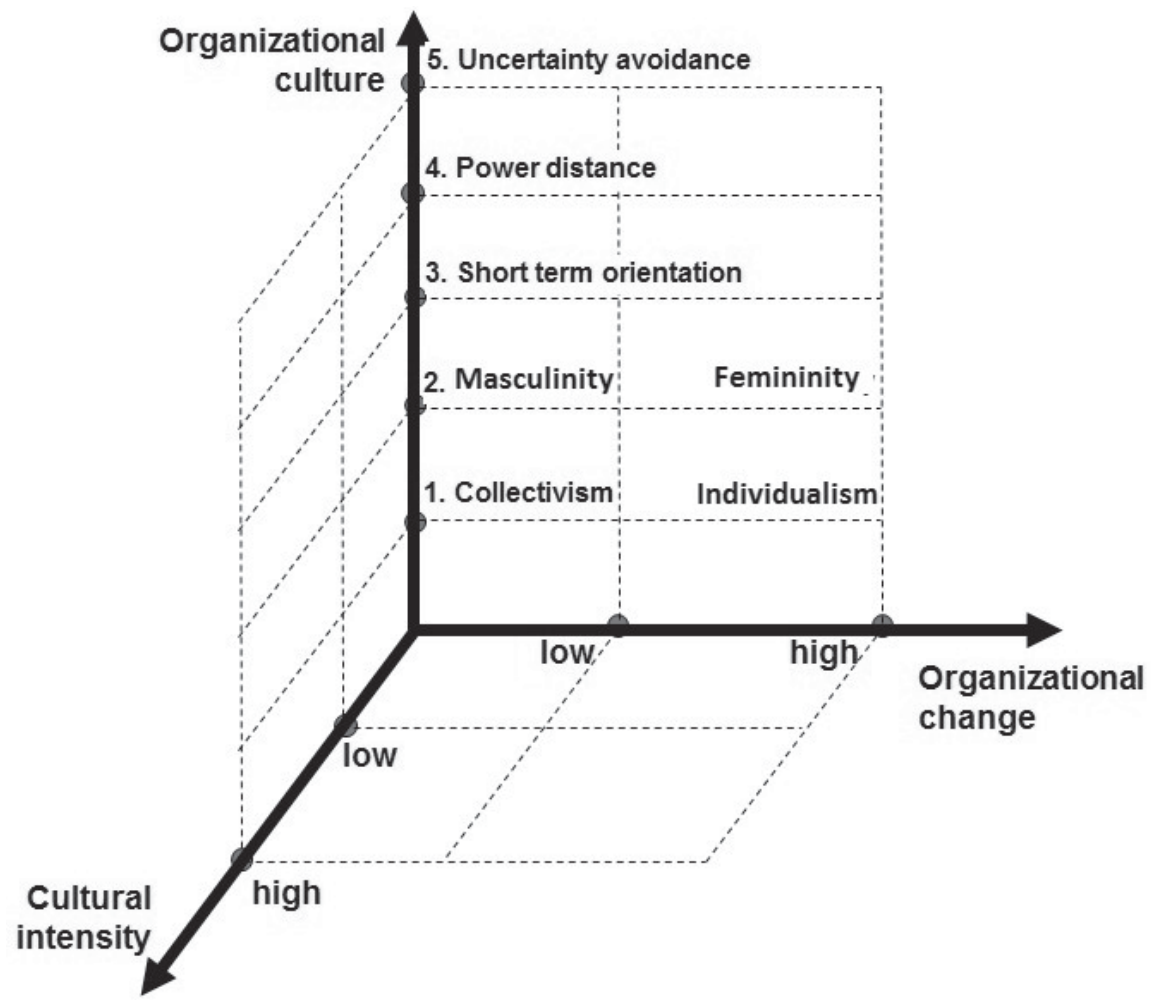

Fig. 1. Morphological matrix of organizational change in natural gases engineering education

In such a situation, the manager will have the role task of moderating and tempering eventual enthusiasms that could set unbalances.

The organization's femininity can also be linked to change.

\section{Low femininity, low wish for change}

The characteristics are those of a collective with weak links between participants, with a certain communication, mainly formal. Because of a low wish for change, the members seem more like passing actors in the organization, rather than its stakeholders, set to build its future. Without the attributes of masculinity, so without the wish to build a strong career path, the participants in the organization act only to conserve a mediocre state of art, concerning both relationships and personal development. 
The manager's task in this situation is to create necessary motivation for the members of the organization. We could also consider eliminating some of them who do not bring a certain added value in order to foster the self-accomplishment of the others.

\section{Low femininity, high wish for change}

This is a very unlikely situation, because femininity is characterized by certain stability. The members of the organization favour good relations and stability that insures the necessary organizational comfort. Without high personal ambitions, without vanity, a change of the status quo is not required, if they already have the necessary climate.

\section{High femininity, low wish for change}

This is the classic case, specific to feminine cultures, where a state of the art considered favourable for group consensus is maintained. Individuals accentuate the stability of the organization, plead for group harmony and sometimes even oppose welcoming new members into the organization in order to prevent any perturbation in the organizational balance. If initially such a situation seams favourable for the organization, in time it will have a negative effect, because of the lack of change. The organization is and must be seen as an open system, with constant interference with signals from the external environment, but in this case signals are blocked, inhibited.

The management of such an organization has the task to build masculinity poles within the organization either by introducing new members who adhere to the masculine culture or by pro-voking those members within the organization who can be steered towards areas of change acceptance. Attention is required in order not to damage the organizational culture.

\section{High femininity, high wish for change}

Again, a very unlikely situation, because femininity appreciates stability, without inflexions, without new challenges, with a high wish for leaving things the way they are.

Without any doubt the management will have a hard time applying the reforms provided by the Education Law no. 1/2011, because the participants in the organization will not easily accept change. This is much more difficult because, in order to have chances of success, change had to be done slowly, over a long period of time in order to keep the organizational balance. But the current situation does not allow for this, as now, in just a month's time, the classification of universities and the ranking of study programs must be done in Romania, and it has already stirred numerous discussions, controversies and even conflicts.

What could empower management is the fact that the first place in the promoted values is lawfulness, which means respecting the law. This leads us to believe that, even though they do not agree with the way that change is operated and they do not share the vision of the current ministerial leadership, members of LBU will still accept to produce the changes 
that are imposed. It remains to be seen how these changes will reflect in the femininity of the organization and if they will disrupt the organizational balance. Also, the promotion of those values which could make change viable and accepted throughout the entire organization is critical [2].

Uncertainty avoidance is another dimension which can easily contradict the change proposed by the new ministerial educational policy. It is accepted for education that applied reforms must first be experimented on small groups of subjects, in order for them not to disrupt the system on a large scale. In our situation, a series of measures are applied, which cannot be found anywhere else in Europe and the effect of which is, currently, very little foreseen and can under no circumstances be interpreted as favourable.

Small power distance translates to change by a general lack of appetite towards change. Members of the organization have the courage to inform their leaders on the lack of involvement in change and it is supposed that common general opinions exist on this topic. In organizations with low power distance and high uncertainty avoidance, the manager's authority is supreme and all activities are done according to well set rules. Taking risks is not cultivated and thus, unwanted. Without any doubt that just this risk taking brought by the new vision on education is the one that will cast a shadow on change, making it hard to accept if not even to be completely rejected by the analysed organization.

\section{CONCLUSIONS}

Of course we must accept the idea that no organization has a monolithic culture, but a mix of cultures, consisting of the analysed cultural dimensions in various proportions. As such, the interventions in order to achieve change can have unsuspected and different effects in the subcultures that compose the University in Sibiu, as we can see in the natural gases engineering education.

The high uncertainty avoidance can be exploited by the university and faculty management in the sense that the organizational members will see their jobs threatened if they do not comply. The problem is if the managers themselves see change as beneficial. Because if they are not convinced by its utility in the way the new education law shapes the educational path, meaning the imposed classification of universities and the ranking of study programs natural gases engineering education has the highest position in Romania, the change will definitely be criticized, contested and rejected.

The organizational culture changes because of the organization's need to adapt to environment changes, but for this to be possible, it is required that values, norms and cultural dimensions allow for flexibility.

The process of organized and intentional change of an organization, in our case of the whole educational system the way it is seen by the new educational law, requires a careful analysis of the elements that will perpetuate change and will contribute to it. Attention must also be given to the point of origin for the change: people, structure or organizational procedures. 


\section{REFERENCES}

[1] Achua C., Lussier R.: Effective Leadership. 4th edition. South-Western CENGACELearning, 2010.

[2] Davidson H.: The Commited Enterprise: How to make Vision and Values to Work. Butterworth-Heinemann, Oxford 2001.

[3] Duse D.M.: Organizational Culture Incentive for Academic Staff Development. 2nd W4SEAS International Conferences on Educational Technologies (EDUTE 2006), Bucharest, Romania 2006.

[4] Duse D.M.: Academic Staff Development through Organisational Culture. European Society for Engineering Education SEFI 2006, Uppsala, Suedia 2006.

[5] Duse C.S.: Influences of the Oragnizational Change on Academic Management Change and Development in Classical Universities. SKEMA Business School, France 2011.

[6] Everard K.B., Morris G., Wilson I.: Effective School Management. 4th edition. SAGE Publications, London 2009.

[7] Greenberg J., Baron R.: Behavior in Organizations. 10th edition. Pearson Education, London 2010.

[8] Hofstede G.: Cultures and organisations: Software of the Mind. Revised and expanded 2nd edition. McGraw-Hill, New York 2005.

[9] McCaffery P.: The Higher Education Manager's Handbook. 2nd edition. Routledge Taylor and Francis Group, New York 2010.

[10] Sackmann S.: Cultural Complexity in Organizations. John Wiley \& Sons, New York 2001.

[11] Talbot M.: Make your Mission Statement Work: How to Identify and Promote the Values of Your Organisation. How to Books, Oxford 2000. 